Article

\title{
An Anisotropic Auxetic 2D Metamaterial Based on Sliding Microstructural Mechanism
}

\author{
Teik-Cheng Lim
}

School of Science and Technology, Singapore University of Social Sciences, Singapore 599494, Singapore; tclim@suss.edu.sg; Tel.: +65-62489252

Received: 27 December 2018; Accepted: 24 January 2019; Published: 30 January 2019

check for updates

\begin{abstract}
A new 2D microstructure is proposed herein in the form of rigid unit cells, each taking the form of a cross with two opposing crossbars forming slots and the other two opposing crossbars forming sliders. The unit cells in the microstructure are arranged in a rectangular array in which the nearest four neighboring cells are rotated by $90^{\circ}$ such that a slider in each unit cell is connected to a slot from its nearest neighbor. Using a kinematics approach, the Poisson's ratio along the axes of symmetry can be obtained, while the off-axis Poisson's ratio is obtained using Mohr's circle. In the special case of a square array, the results show that the Poisson's ratio varies between 0 (for loading parallel to the axes) and -1 (for loading at $45^{\circ}$ from the axes). For a rectangular array, the Poisson's ratio varies from 0 (for loading along the axes) to a value more negative than -1 . The obtained results suggest the proposed microstructure is useful for designing materials that permit rapid change in Poisson's ratio for angular change.
\end{abstract}

Keywords: anisotropic; auxetic; metamaterials; microstructure; slot and slider mechanism

\section{Introduction}

Auxetic materials are solids that exhibit a negative Poisson's ratio, i.e., such materials expand laterally when stretched axially and contract laterally when compressed axially and are therefore classified under the broad category of metamaterials with negative properties. Metamaterials are materials that are engineered to possess characteristics that are not exhibited in naturally occurring materials; they consist of smaller units arranged in such a manner that the metamaterial behavior arises from the geometrical microstructures rather than from that of the base material. Research in auxetic materials began in earnest with the works of Lakes [1,2] and Wojciechowski et al. [3-5], leading to a great number of potential applications [6-23]. Due to the negativity of Poisson's ratio, auxetic fibers are resistant towards pull-out from the matrix material because the tensile load of the fiber causes the fiber diameter to increase, thereby producing a self-locking mechanism. Auxetic sheets are suitable for wrapping around dome-shaped surfaces because the action of bending on two opposing sides of the sheet material causes the other two sides to curve in similar way to form a synclastic shape. In addition, an auxetic half-space is useful for reinforcing against projectile impact because the action of point load on a surface causes the material to move radially towards the line of force. Pertaining to the last example, Shodja et al. [24] showed a very strong influence of the Poisson's ratio, via the elastic constants, on Boussinesq indentation of a transversely isotropic half-space embedded with an inextensible membrane.

The application of auxetic materials vis-à-vis conventional ones is of interest as the overall properties of structures made of auxetic materials differ from-and, under some circumstances, are not achievable by-structures made from conventional ones. By way of example, a study of the axisymmetric response of a bi-material full-space with an interfacial thin film by Ahmadi et al. [25] showed that in a reinforced homogeneous full-space made from materials with small positive Poisson's 
ratio or with negative Poisson's ratio, the thin film reinforcement has an insignificant influence on elastic responses. In addition, reinforced full-spaces made of auxetic materials exhibit more compliant properties in comparison to reinforced conventional materials [25].

Of late, progress has been made on planar tessellations that are capable of controlling the Poisson's ratio, including triggering auxetic behavior [26,27]. In addition to the microstructural level, auxeticity can also be derived by introducing perforations [28] and other forms of porosity [29,30]. Due to an exponential increase in this area of research in the past decades, it is no longer possible to list relevant works sufficiently. The reader is referred to recent comprehensive reviews in auxetic materials [31-36] and a related monograph [37]. The proposed microstructure resembles the interlocking hexagons model [38], in which no microstructural rotation occurs, but, instead, sliding takes place between neighboring blocks. Essentially, the unit cells are rigid or of a very high stiffness such that the assumption of rigid units is valid and only translational motion takes place. One such example has been suggested by Alderson and Scarpa [39] in regard to eliminating mechanical vibrations and noise experienced by newborn babies during transfer in vehicles, whereby the interlocking model could be used to help make safer neonatal transfer vehicles.

In this paper, a 2D metamaterial is proposed to exhibit zero Poisson's ratio along its principal axes, while exhibiting negative values of Poisson's ratio in other directions, i.e., the microstructure exhibits great sensitivity in change in Poisson's ratio from change in loading direction. The proposed 2D metamaterial and some of its deformation mechanisms are illustrated in Figure 1. Each unit cell is rigid and takes the form of a cross such that two opposing crossbars are slots and the other two opposing crossbars are sliders, as shown in Figure 1a. The unit cells in the microstructure are arranged in a rectangular array with the nearest four neighboring cells rotated by $90^{\circ}$ so that a slider from one cell is placed in the slot of its neighbor. A sample of $4 \times 4$ unit cells that make up the microstructure is furnished in Figure 1b. This indicates the microstructural conformation at the original, or undeformed, state; a dashed purple square that encompasses the given microstructure before deformation is imposed on the microstructure with deformation so as to facilitate comparison against the former. Under loading along the $y$ direction, as shown in Figure 1c, the Poisson's ratio is $v_{y x}=0$, while loading in the direction of the $x$ axis, as shown in Figure $1 \mathrm{~d}$, gives $v_{x y}=0$. Under the action of off-axis loading, as indicated in Figure 1e, we have a negative Poisson's ratio. The underlying hypothesis requires that the relative motion of each unit, with reference to its neighboring unit cell, is uniform. It follows that the increase or decrease in the gap is uniform when measured from each axis. It is further assumed that the contact areas between the slot and slider are frictionless, or that the effect of friction is negligible, as a result of sufficient lubrication. With the advancement of rapid prototyping technology, the currently proposed microstructure can be designed and fabricated using 3D printing or kirigami manufacture. 


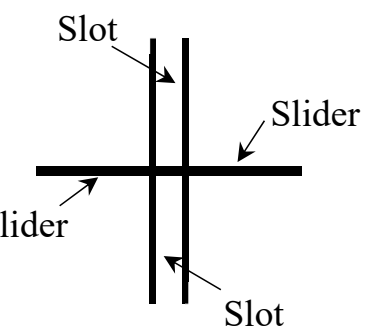

(a)
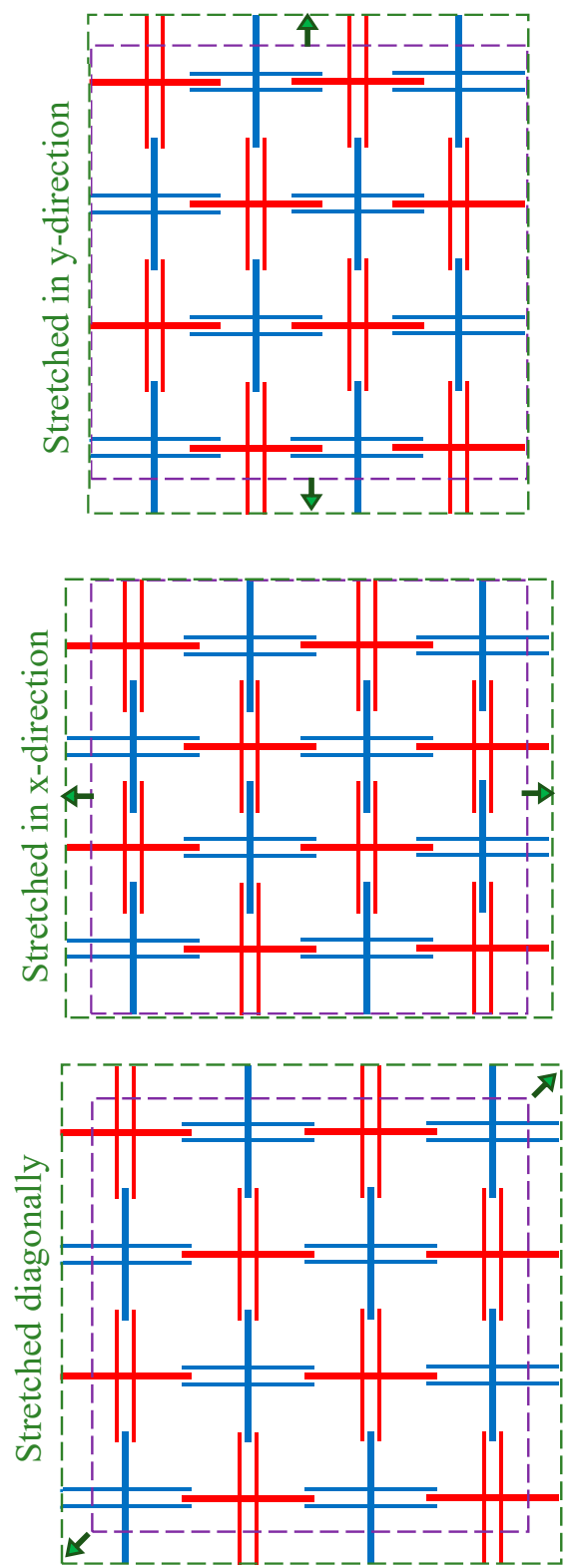

(b)

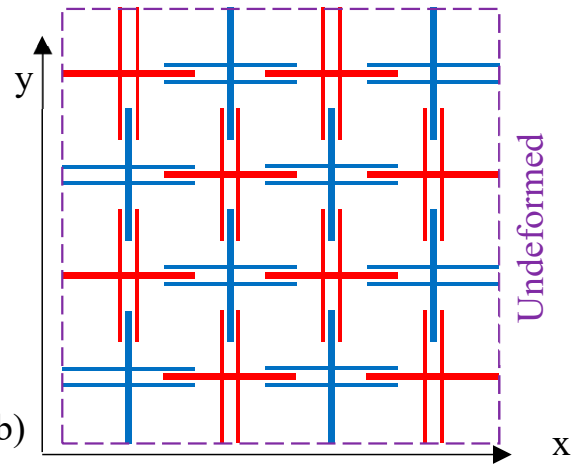

(c)

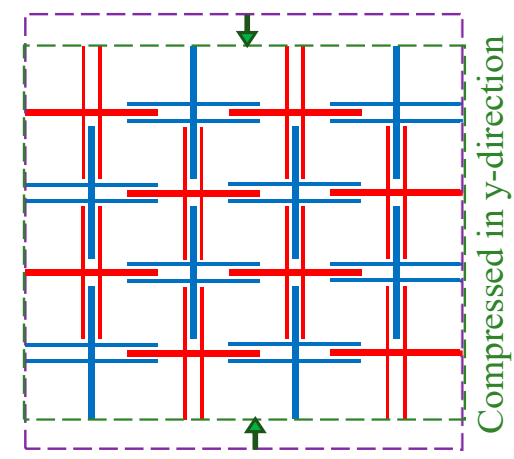

(d)

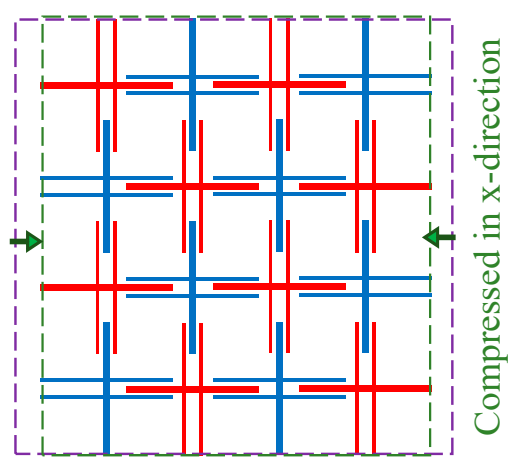

(e)

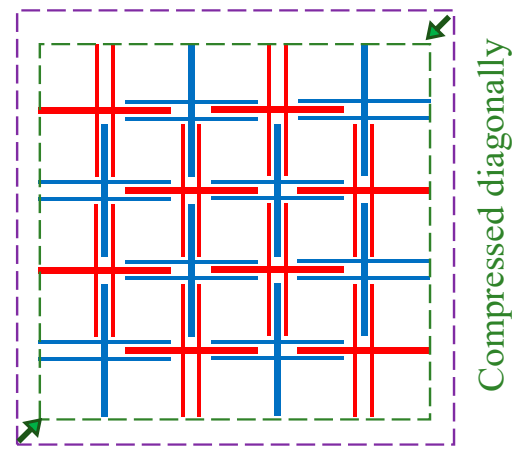

Figure 1. (a) A unit cell of the microstructure; (b) $4 \times 4$ unit cells in the original state; (c) loading in the $y$ direction; (d) loading in the $x$ direction; and (e) off-axis loading. Note: the dashed purple squares indicate the undeformed boundaries, while the dashed green squares or rectangles denote deformed boundaries. 


\section{Analysis}

The analysis of Poisson's ratio for the proposed 2D metamaterial is made in reference to Figure 2, wherein neighboring unit cells are spaced at distances of $x_{0}$ and $y_{0}$ along the $x$ axis and $y$ axis, respectively. While the analysis of Poisson's ratio values $v_{x y}$ and $v_{y x}$ can be easily made by sliding cell $\mathrm{A}$ along the $x$ axis and by sliding cell $\mathrm{B}$ along the $y$ axis, such an approach does not permit the analysis of the Poisson's ratio in the other direction. Hence, a general approach can be attempted by taking the displacement of cell $\mathrm{C}$ with respect to cell $\mathrm{O}$, which the origin of the coordinate system lies on. Let $\theta$ indicate the loading direction. By symmetry, it is sufficient to model the movement of $\mathrm{C}$ for $0^{\circ}<\theta<90^{\circ}$. The movement of $C$ in the direction $90^{\circ}<\theta<180^{\circ}$ is not defined as it would be appropriate to model the displacement of cell $\mathrm{E}$ in that direction with reference to cell O. Similarly, the motion of $\mathrm{C}$ in the direction $270^{\circ}<\theta<360^{\circ}$ is undefined, as it would be proper to do so for cell $\mathrm{F}$ in that direction with reference to cell $\mathrm{O}$. The displacement of $\mathrm{C}$ in the direction $180^{\circ}<\theta<270^{\circ}$ indicates compressive loading, but this is not required as the analysis of loading in the $0^{\circ}<\theta<90^{\circ}$ direction includes that in the $180^{\circ}<\theta<270^{\circ}$ direction by using negative values for the displacement components.

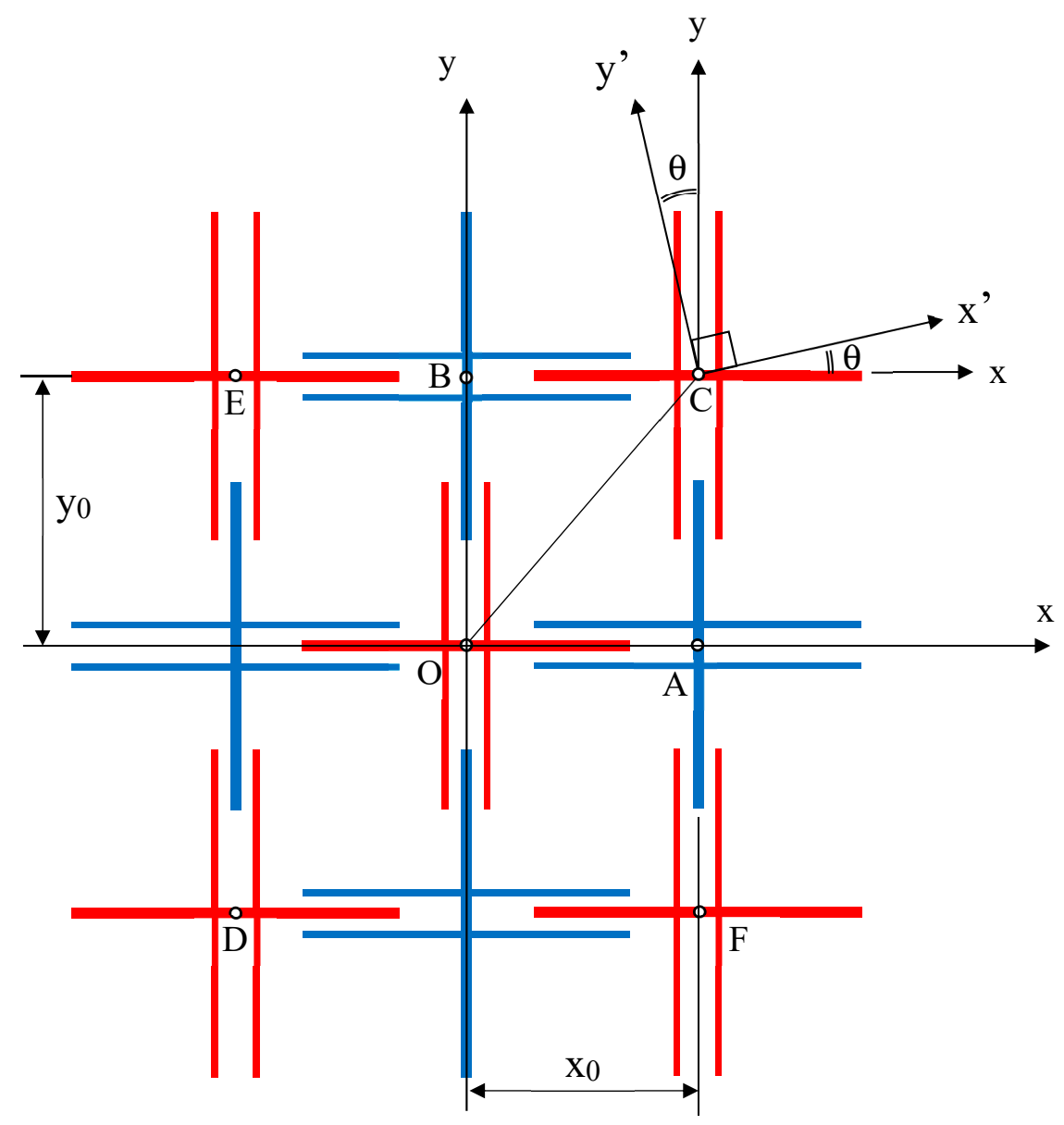

Figure 2. Schematic view for analysis.

To cater for off-axis loading, we introduce on the cell $C$ the local $x^{\prime}-y^{\prime}$ axes, which are rotated by an angle of $\theta$ anti-clockwise from the global $x-y$ axes, such that the $x^{\prime}$ axis coincides with the loading direction. Let cell $\mathrm{C}$ displace by a distance $d x^{\prime}$. Resolving the $\mathrm{d} x^{\prime}$ displacement along the $x$ axis and the $y$ axis, we have

$$
\begin{aligned}
& d x=d x / \cos \theta \\
& d y=d x / \sin \theta
\end{aligned}
$$


which lead to the corresponding strains

$$
\begin{aligned}
& \varepsilon_{x}=\frac{d x}{x_{0}}=\frac{d x \prime}{x_{0}} \cos \theta \\
& \varepsilon_{y}=\frac{d y}{y_{0}}=\frac{d x \prime}{y_{0}} \sin \theta
\end{aligned}
$$

in the $x$ axis and $y$ axis, respectively. Since the $x$ and $y$ axes are axes of symmetry, the corresponding strains are principal strains. Upon recognizing that Equation (2) gives the principal strains, the strains in the $x^{\prime}$ and $y^{\prime}$ directions can be obtained using Mohr's circle for strain, as shown in the Appendix A. From Figure A1 of the Appendix A, we have

$$
\varepsilon_{A V E}=\frac{\varepsilon_{x}+\varepsilon_{y}}{2}=\frac{d x \prime}{2}\left(\frac{\cos \theta}{x_{0}}+\frac{\sin \theta}{y_{0}}\right)
$$

and

$$
R=\frac{\varepsilon_{x}-\varepsilon_{y}}{2}=\frac{d x \prime}{2}\left(\frac{\cos \theta}{x_{0}}-\frac{\sin \theta}{y_{0}}\right)
$$

which lead to the strains in the direction of loading $x^{\prime}$ of

$$
\varepsilon_{x \prime}=\varepsilon_{A V E}+R \cos 2 \theta=\frac{d x \prime}{2}\left[\frac{\cos \theta}{x_{0}}(1+\cos 2 \theta)+\frac{\sin \theta}{y_{0}}(1-\cos 2 \theta)\right]
$$

and in the direction perpendicular to the direction of loading of

$$
\varepsilon_{y \prime}=\varepsilon_{A V E}-R \cos 2 \theta=\frac{d x \prime}{2}\left[\frac{\cos \theta}{x_{0}}(1-\cos 2 \theta)+\frac{\sin \theta}{y_{0}}(1+\cos 2 \theta)\right]
$$

The off-axis Poisson's ratio, $v_{x^{\prime} y^{\prime}}$, is therefore

$$
v_{x \prime y \prime}=-\frac{\varepsilon_{y \prime}}{\varepsilon_{x \prime}}=-\frac{\frac{\cos \theta}{x_{0}}(1-\cos 2 \theta)+\frac{\sin \theta}{y_{0}}(1+\cos 2 \theta)}{\frac{\cos \theta}{x_{0}}(1+\cos 2 \theta)+\frac{\sin \theta}{y_{0}}(1-\cos 2 \theta)}
$$

It can be seen that the substitution of $\theta=0^{\circ}$ (i.e., $v_{x^{\prime} y^{\prime}}=v_{x y}$ ) into Equation (7) gives $v_{x^{\prime} y^{\prime}}=0$, and likewise the substitution of $\theta=90^{\circ}$ (i.e., $v_{x^{\prime} y^{\prime}}=v_{y x}$ ) into Equation (7) also gives $v_{x^{\prime} y^{\prime}}=0$. The Poisson's ratio results for off-axis loading are discussed in the next section.

\section{Results and Discussion}

If the cells are arranged such that $\mathrm{OC}$ makes an angle of $30^{\circ}$ with the $x$ axis (i.e., $y_{0}=x_{0} / \sqrt{ } 3$ ) or $60^{\circ}$ with the $x$ axis (i.e., $y_{0}=x_{0} \sqrt{ } 3$ ), then the off-axis Poisson's ratio equations simplify to

$$
v_{x \prime y \prime}=-\frac{\cos \theta(1-\cos 2 \theta)+\sqrt{3} \sin \theta(1+\cos 2 \theta)}{\cos \theta(1+\cos 2 \theta)+\sqrt{3} \sin \theta(1-\cos 2 \theta)}
$$

and

$$
v_{x \prime} y^{\prime}=-\frac{\sqrt{3} \cos \theta(1-\cos 2 \theta)+\sin \theta(1+\cos 2 \theta)}{\sqrt{3} \cos \theta(1+\cos 2 \theta)+\sin \theta(1-\cos 2 \theta)}
$$

respectively. For the special case of a square array (i.e., $y_{0}=x_{0}$ ), the Poisson's ratio is further reduced to

$$
v_{x \prime y^{\prime}}=-\frac{\cos \theta(1-\cos 2 \theta)+\sin \theta(1+\cos 2 \theta)}{\cos \theta(1+\cos 2 \theta)+\sin \theta(1-\cos 2 \theta)}
$$

The variation of the off-axis Poisson's ratio with the direction of loading for these three spatial arrays is plotted in Figure 3. It can be seen that the most negative Poisson's ratio for a square array occurs when loading is imposed in the diagonal direction, with a value of -1 . A greater extent 
of auxeticity is obtained when the cell array is not square $\left(y_{0} \neq x_{0}\right)$. Specifically, the minimum $v_{x^{\prime} y^{\prime}}$ for a rectangular array is more negative than -1 due to the highly anisotropic nature of this microstructural mechanism.

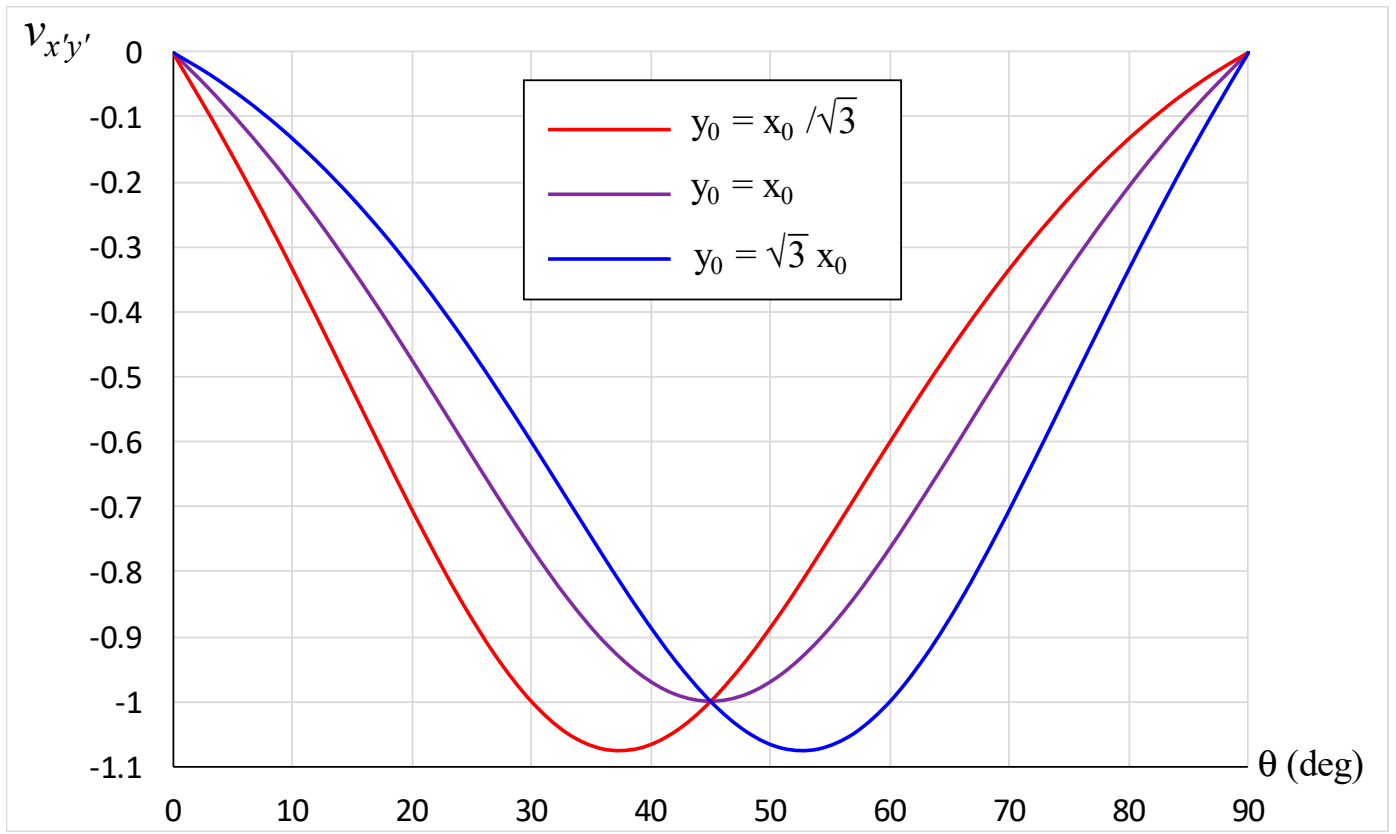

Figure 3. Variation of Poisson's ratio with loading direction for a square array $y_{0}=x_{0}$ (purple) and for rectangular arrays with $y_{0}=\sqrt{3} x_{0}$ (blue) and $y_{0}=x_{0} / \sqrt{3}$ (red).

Particular case studies can be made for the situation wherein the loading direction is parallel to OC in Figure 2. This occurs when the unit cells in the first and third quadrants are stretched away from, or compressed towards, the origin. A similar effect is obtained when the unit cells in the second and fourth quadrants are loaded such that the line of force passes through O. Under such a category, we note that

$$
\tan \theta=\frac{y_{0}}{x_{0}}
$$

Substituting Equation (11) into Equation (7) gives $v_{x^{\prime} y^{\prime}}=-1$. This result is displayed in Figure 3 for $\theta=30^{\circ}, 45^{\circ}$, and $60^{\circ}$ when $y_{0} / x_{0}=\tan 30^{\circ}, y_{0} / x_{0}=\tan 45^{\circ}$, and $y_{0} / x_{0}=\tan 60^{\circ}$, respectively. Another set of particular cases takes place when the array is extreme, such that Equation (7) simplifies to

$$
v_{x \prime y \prime}=-\frac{1 \pm \cos 2 \theta}{1 \mp \cos 2 \theta}
$$

where the upper and lower signs correspond to $y_{0}<<x_{0}$ and $y_{0}>>x_{0}$, respectively. This is shown in Figure $4 \mathrm{a}$ to facilitate comparison between the Poisson's ratio for extreme arrays $\left(y_{0}<<x_{0}\right.$ and $\left.y_{0}>>x_{0}\right)$ with that for moderate arrays $\left(y_{0}=x_{0}, y_{0}=\sqrt{3} x_{0}\right.$, and $\left.y_{0}=x_{0} / \sqrt{3}\right)$. Figure $4 \mathrm{~b}$ demonstrates the manner in which the Poisson's ratio changes as the loading direction approaches the axes. 


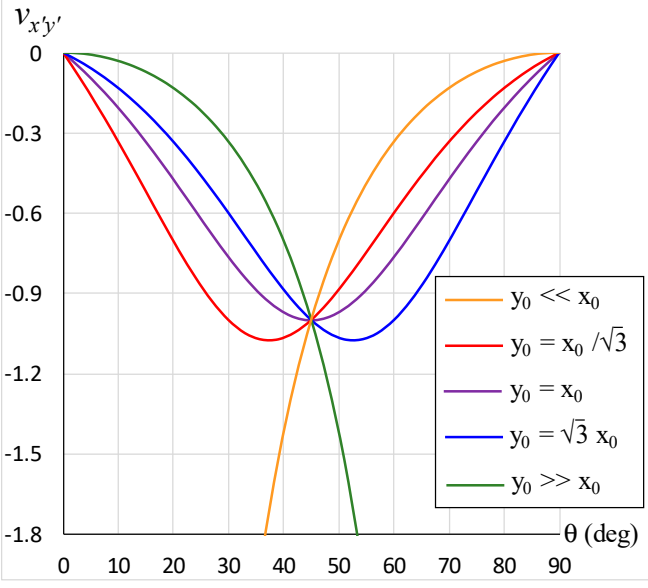

(a)

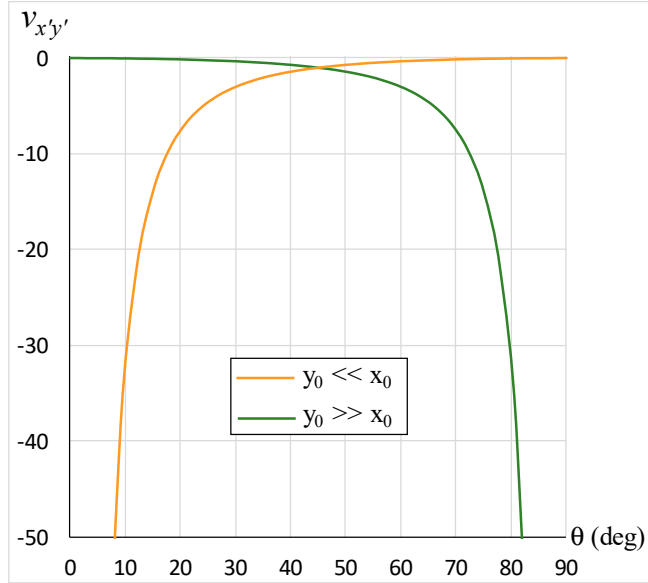

(b)

Figure 4. Variation of Poisson's ratio with loading direction for extreme arrays (yellow and green): (a) in comparison to moderate arrays (red, purple and blue), and (b) a visual display on the extent of auxeticity.

As the current model assumes rigid unit cells, one may expect the actual properties to deviate if the deformation of the unit cells is significant. Specifically, the flexure of the slots and sliders as beam deflections would reduce the strains perpendicular to the direction of the deflected slots and sliders. However, with sufficient lubrication between the slot of a unit cell and the slider in a neighboring unit cell, the suggested microstructure permits smooth relative motion between neighboring unit cells with insignificant deformation of the unit cells. Evidence of this observation is furnished in Figure 5 with a square array $\left(x_{0}=y_{0}\right)$ for $(a)$ the original state, as well as for $(b)$ stretching and (c) compression along $\theta=45^{\circ}$, while stretching and compression along the axes are shown in Figure $5 \mathrm{~d}-\mathrm{g}$.

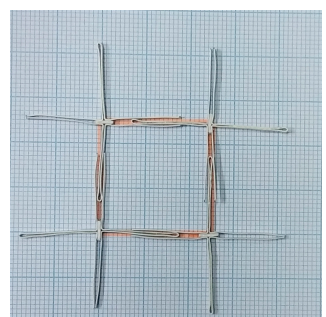

(a)

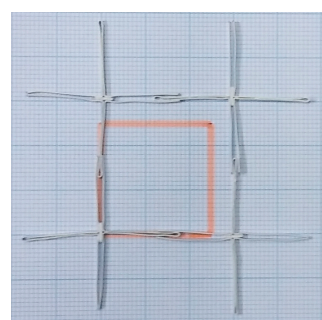

(b)

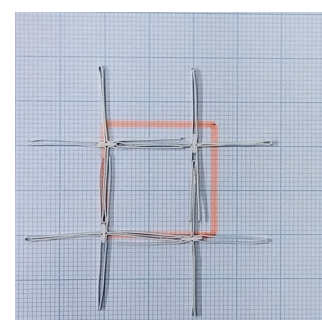

(c)

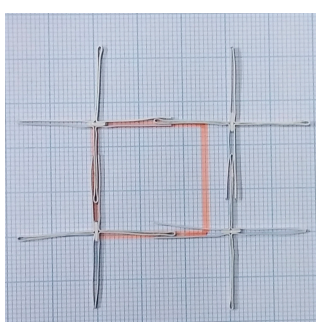

(d)

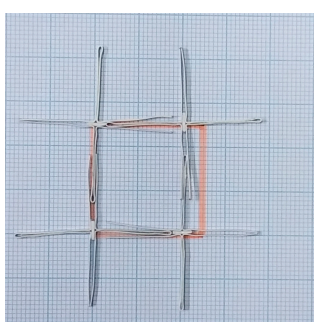

(e)

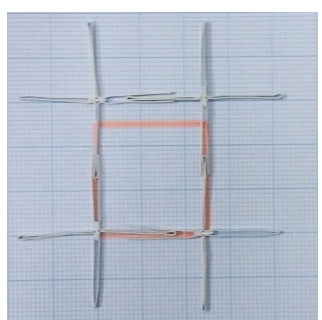

(f)

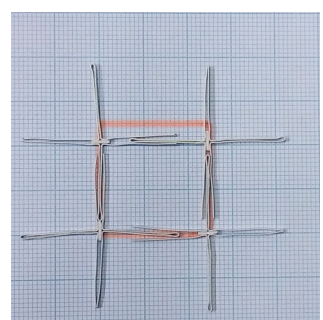

(g)

Figure 5. Proof-of-concept demonstration for the currently described sliding microstructural mechanism using four unit cells: (a) $\varepsilon_{x}=\varepsilon_{y}=0$, (b) $\varepsilon_{x}=\varepsilon_{y}=0.2$, (c) $\varepsilon_{x}=\varepsilon_{y}=-0.2$, (d) $\varepsilon_{x}=0.2, \varepsilon_{y}=0$, (e) $\varepsilon_{x}=-0.2, \varepsilon_{y}=0$, (f) $\varepsilon_{x}=0, \varepsilon_{y}=0.2$, and (g) $\varepsilon_{x}=0, \varepsilon_{y}=-0.2$. An orange-colored square indicates the area formed by the center of the four unit cells before deformation (a) to facilitate comparison with (b) to (g). 


\section{Conclusions}

While most auxetic microstructures exhibit some form of rotation, with the exception of the interlocking hexagons model [38], a new microstructure that is based on sliding mechanism is proposed herein. Unlike the interlocking hexagons model, the currently proposed model exhibits a high level of porosity, and therefore more suitable for applications where low weight is desired. In general, the model demonstrates two axes of symmetry, but the axes of symmetry increase to four in the case of a square array. For the special case of a square array, the Poisson's ratio fluctuates between 0 and -1 for every $45^{\circ}$ change in loading direction. A greater extent of auxeticity can be found when the array is not square. This is due to the high level of anisotropy of the microstructure. The extent of anisotropy increases when the array goes to the extremes, thereby leading to extreme negative Poisson's ratios. The results from this paper, in conjunction with earlier works on auxetic beams $[40,41]$, auxetic rods [42-44], auxetic plates [45-52], auxetic shells [53,54], auxetic composites [55-62] and 2D metamaterial structures $[63,64]$, would avail more design options for the engineer in developing novel load bearing materials and structures.

Funding: This research received no external funding.

Conflicts of Interest: The author declares no conflicts of interest.

\section{Appendix A}

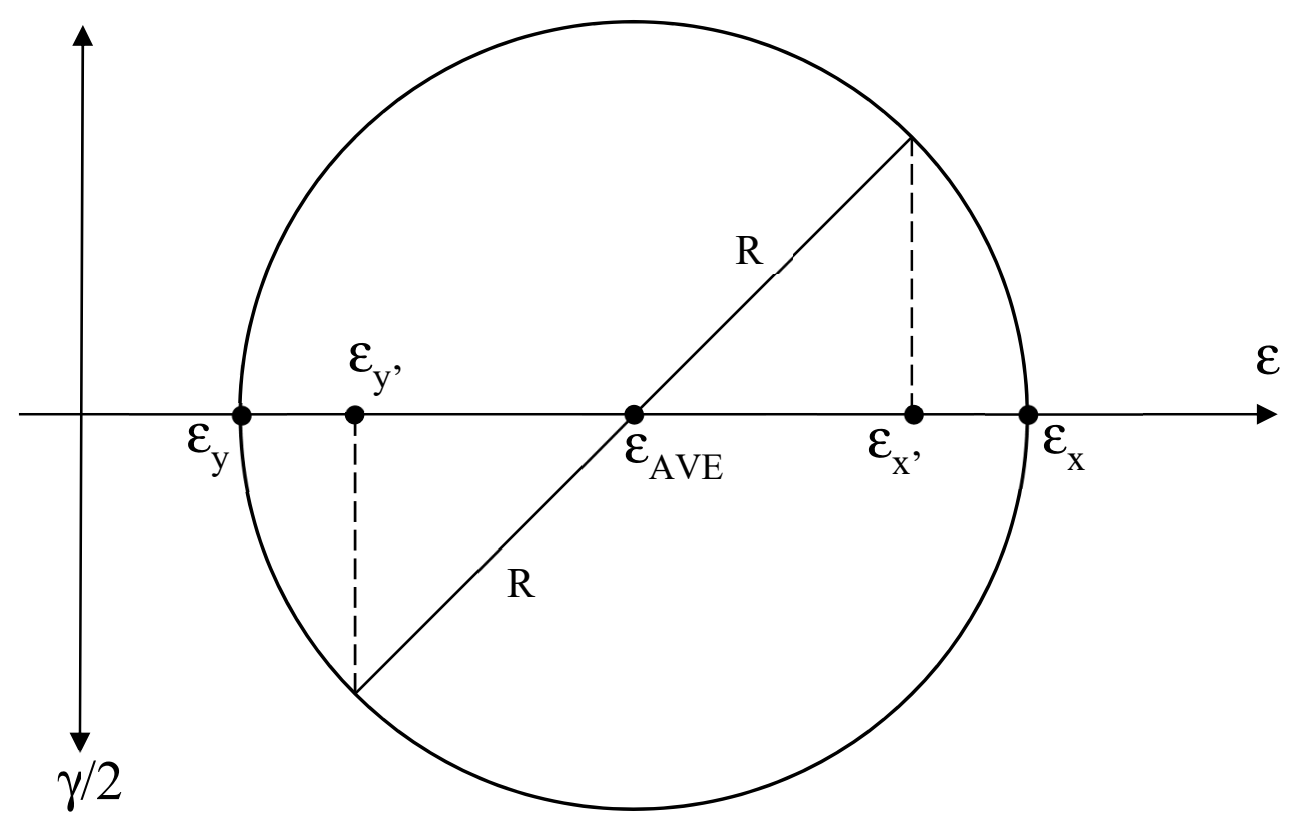

Figure A1. Obtaining the strains parallel and perpendicular to loading direction $\left(x^{\prime}, y^{\prime}\right)$ from the strains along the axes of symmetry $(x, y)$.

\section{References}

1. Lakes, R. Foam structures with negative Poisson's ratio. Science 1987, 235, 1038-1040. [CrossRef] [PubMed]

2. Lakes, R. Negative Poisson's ratio materials. Science 1987, 238, 551. [CrossRef] [PubMed]

3. Wojciechowski, K.W. Constant thermodynamic tension Monte-Carlo studies of elastic properties of a two-dimensional system of hard cyclic hexamers. Mol. Phys. 1987, 61, 1247-1258. [CrossRef]

4. Wojciechowski, K.W. Two-dimensional isotropic system with a negative Poisson ratio. Phys. Lett. A 1989, 137, 60-64. [CrossRef]

5. Wojciechowski, K.W.; Branka, A.C. Negative Poisson ratio in a two-dimensional "isotropic" solid. Phys. Rev. A 1989, 40, 7222-7225. [CrossRef] 
6. Choi, J.B.; Lakes, R.S. Design of a fastener based on negative Poisson's ratio foam. Cell. Polym. 1991, 10, 205-212.

7. Caddock, B.D.; Evans, K.E. Negative Poisson ratios and strain-dependent mechanical properties in arterial prostheses. Biomaterials 1995, 16, 1109-1115. [CrossRef]

8. Martz, E.O.; Lakes, R.S.; Goel, V.K.; Park, J.B. Design of an artificial intervertebral disc exhibiting a negative Poisson's ratio. Cell. Polym. 2005, 24, 127-138. [CrossRef]

9. Dolla, W.J.S.; Fricke, B.A.; Becker, B.R. Structural and drug diffusion models of conventional and auxetic drug-eluting stents. J. Med. Dev. 2007, 1, 47-55. [CrossRef]

10. Scarpa, F. Auxetic materials for bioprostheses. IEEE Signal Process. Mag. 2008, 25, 125-126. [CrossRef]

11. Lakes, R.S.; Lowe, A. Negative Poisson's ratio foam as seat cushion material. Cell. Polym. 2000, 19, 157-167.

12. Wang, Y.C.; Lakes, R.S. Analytical parametric analysis of the contact problem of human buttocks and negative Poisson's ratio foam cushions. Int. J. Solids Struct. 2002, 39, 4825-4838. [CrossRef]

13. Alderson, A.; Rasburn, J.; Ameer-Bag, S.; Mullarkey, P.G.; Perrie, W.; Evans, K.E. An auxetic filter: A tuneable filter displaying enhanced size selectivity or defouling properties. Ind. Eng. Chem. Res. 2000, 39, 654-655. [CrossRef]

14. Alderson, A.; Davies, P.J.; Evans, K.E.; Alderson, K.L.; Grima, J.N. Modelling of the mechanical and mass transport properties of auxetic molecular sieves: An idealised inorganic (zeolitic) host-guest system. Mol. Simul. 2005, 31, 889-896. [CrossRef]

15. Alderson, A.; Davies, P.J.; Williams, M.R.; Evans, K.E.; Alderson, K.L.; Grima, J.N. Modelling of the mechanical and mass transport properties of auxetic molecular sieves: An idealised organic (polymeric honeycomb) host-guest system. Mol. Simul. 2005, 31, 897-905. [CrossRef]

16. Lim, T.C.; Acharya, R.U. Performance Evaluation of Auxetic Molecular Sieves with Re-Entrant Structures. J. Biomed. Nanotechnol. 2010, 6, 718-724. [CrossRef]

17. Scarpa, F.; Giacomin, J.; Zhang, Y.; Pastorino, P. Mechanical performance of auxetic polyurethane foam for antivibration glove applications. Cell. Polym. 2005, 24, 253-268. [CrossRef]

18. Alderson, A.; Alderson, K.L. Expanding materials and applications: Exploiting auxetic textiles. Tech. Text. Int. 2005, 14, 29-34.

19. Park, K.O.; Choi, J.B.; Lee, S.J.; Choi, H.H.; Kim, J.K. Polyurethane foam with Negative Poisson's ratio for diabetic shoe. Key Eng. Mater. 2005, 288-289, 677-680. [CrossRef]

20. Ellul, B.; Muscat, M.; Grima, J.N. On the effect of the Poisson's ratio (positive and negative) on the stability of pressure vessel heads. Phys. Status Solidi B 2009, 246, 2025-2032. [CrossRef]

21. Salit, V.; Weller, T. On the feasibility of introducing auxetic behavior into thin-walled structures. Acta Mater. 2009, 57, 125-135. [CrossRef]

22. Whitty, J.P.M.; Henderson, B.; Myler, P.; Chirwa, C. Crash performance of cellular foams with reduced relative density part 2: Rib deletion. Int. J. Crashworthiness 2007, 12, 689-698.

23. Park, K.O.; Choi, J.B.; Park, J.C.; Park, D.J.; Kim, J.K. An improvement in shock absorbing behavior of polyurethane foam with a negative Poisson effect. Key Eng. Mater. 2007, 342-343, 845-848. [CrossRef]

24. Shodja, H.M.; Ahmadi, S.F.; Eskandari, M. Boussinesq indentation of a transversely isotropic half-space reinforced by a buried inextensible membrane. Appl. Math. Model. 2014, 38, 2163-2172. [CrossRef]

25. Ahmadi, S.F.; Samea, P.; Eskandari, M. Axisymmetric response of a bi-material full-space reinforced by an interfacial thin film. Int. J. Solids Struct. 2016, 90, 251-260. [CrossRef]

26. Mitschke, H.; Schwerdtfeger, J.; Schury, F.; Stingl, M.; Körner, C.; Singer, R.F.; Robins, V.; Mecke, K.; Schröder-Turk, G.E. Finding auxetic frameworks in periodic tessellations. Adv. Mater. 2011, 23, 2669-2674. [CrossRef]

27. Mitschke, H.; Robins, V.; Mecke, K.; Schröder-Turk, G.E. Finite auxetic deformations of plane tessellations. Proc. R. Soc. A 2013, 469, 20120465. [CrossRef]

28. Grima, J.N.; Gatt, R. Perforated sheets exhibiting negative Poisson's ratios. Adv. Eng. Mater. 2010, 12, 460-464. [CrossRef]

29. Taylor, M.; Francesconi, L.; Gerendás, M.; Shanian, A.; Carson, C.; Bertoldi, K. Low porosity metallic periodic structures with negative Poisson's ratio. Adv. Mater. 2014, 26, 2365-2370. [CrossRef]

30. Francesconi, L.; Taylor, M.; Bertoldi, K.; Baldi, A. Static and modal analysis of low porosity thin metallic auxetic structures using speckle interferometry and digital image correlation. Exp. Mech. 2018, 58, 283-300. [CrossRef] 
31. Jiang, J.W.; Kim, S.Y.; Park, H.S. Auxetic nanomaterials: Recent progress and future development. Appl. Phys. Rev. 2016, 3, 041101. [CrossRef]

32. Saxena, K.K.; Das, R.; Calius, E.P. Three decades of auxetics research-Materials with negative Poisson's ratio: A review. Adv. Eng. Mater. 2016, 18, 1847-1870. [CrossRef]

33. Park, H.S.; Kim, S.Y. A perspective on auxetic nanomaterials. Nano Converg. 2017, 4, 10. [CrossRef] [PubMed]

34. Lim, T.C. Analogies across auxetic models based on deformation mechanism. Phys. Status Solidi RRL 2017, 11, 1600440. [CrossRef]

35. Kolken, H.M.A.; Zadpoor, A.A. Auxetic mechanical metamaterials. RSC Adv. 2017, 7, 5111-5129. [CrossRef]

36. Lakes, R.S. Negative-Poisson's-ratio materials: Auxetic solids. Ann. Rev. Mater. Res. 2017, 47, 63-81. [CrossRef]

37. Lim, T.C. Auxetic Materials and Structures; Springer: Singapore, 2015; ISBN 978-981-287-274-6.

38. Ravirala, N.; Alderson, A.; Alderson, K.L. Interlocking hexagons model for auxetic behavior. J. Mater. Sci. 2007, 42, 7433-7445. [CrossRef]

39. Alderson, A.; Scarpa, F. We've Created a New Vibration-Proof 'Metamaterial' That Could Save Premature Babies' Lives. The Conversation, 2017. Available online: https:/ / theconversation.com/weve-created-a-newvibration-proof-metamaterial-that-could-save-premature-babies-lives-70872 (accessed on 30 January 2019).

40. Lim, T.C. Functionally graded beam for attaining Poisson-curving. J. Mater. Sci. Lett. 2002, 21, $1899-1901$. [CrossRef]

41. Lim, T.C. Shear deformation in beams with negative Poisson's ratio. J. Mater. Des. Appl. 2015, $229,447-454$. [CrossRef]

42. Lim, T.C. Torsion of semi-auxetic rods. J. Mater. Sci. 2011, 46, 6904-6909. [CrossRef]

43. Lim, T.C. Longitudinal wave velocity in auxetic rods. J. Eng. Mater. Technol. 2015, 137, 024502. [CrossRef]

44. Lim, T.C. Auxeticity of concentric auxetic-conventional foam rods with high modulus interface adhesive. Materials 2018, 11, 223. [CrossRef]

45. Sobieszczyk, P.; Majka, M.; Kuźma, D.; Lim, T.C.; Zieliński, P. Effect of longitudinal stress on wave propagation in width-constrained elastic plates with arbitrary Poisson's ratio. Phys. Status Solidi B 2015, 252, 1615-1619. [CrossRef]

46. Lim, T.C. Bending stresses in triangular auxetic plates. J. Eng. Mater. Technol. 2016, 138, 014501. [CrossRef]

47. Lim, T.C. Longitudinal wave motion in width-constrained auxetic plates. Smart Mater. Struct. 2016, 25, 054008. [CrossRef]

48. Lim, T.C. Simply-supported elliptical auxetic plates. J. Mech. 2016, 32, 413-419. [CrossRef]

49. Lim, T.C. An accurate design equation for the maximum deflection in a class of auxetic sectorial plates. Phys. Status Solidi B 2017, 254, 1600784. [CrossRef]

50. Lim, T.C. Shear deformation in a class of thick hexagonal plates. Phys. Status Solidi B 2017, $254,1700014$. [CrossRef]

51. Lim, T.C. Refined shear correction of polygonal plates with static loads. Proc. Inst. Civil Eng. - Eng. Comput. Mech. 2017, 170, 167-173. [CrossRef]

52. Gorodtsov, V.A.; Lisovenko, D.S.; Lim, T.C. Three-layered plate exhibiting auxeticity based on stretching and bending modes. Compos. Struct. 2018, 194, 643-651. [CrossRef]

53. Lim, T.C. Spherical auxetic shells. Adv. Mater. Res. 2013, 804, 146-150. [CrossRef]

54. Lim, T.C. Thermal stresses in auxetic plates and shells. Mech. Adv. Mater. Struct. 2015, 22, 205-212. [CrossRef]

55. Lim, T.C. Out-of-plane modulus of semi-auxetic laminates. Eur. J. Mech. A Solids 2009, 28, 752-756. [CrossRef]

56. Lim, T.C. In-plane stiffness of semiauxetic laminates. J. Eng. Mech. 2010, 136, 1176-1180. [CrossRef]

57. Lim, T.C.; Acharya, U.R. Longitudinal modulus of semi-auxetic unidirectional fiber composites. J. Reinf. Plast. Compos. 2010, 29, 1441-1445. [CrossRef]

58. Lim, T.C. Coefficient of thermal expansion of stacked auxetic and negative thermal expansion laminates. Phys. Status Solidi B 2011, 248, 140-147. [CrossRef]

59. Lim, T.C.; Rajendra Acharya, U. Counterintuitive modulus from semi-auxetic laminates. Phys. Status Solidi B 2011, 248, 60-65. [CrossRef]

60. Lim, T.C. Mixed auxeticity of auxetic sandwich structures. Phys. Status Solidi B 2012, 249, $1366-1372$. [CrossRef]

61. Boldrin, L.; Hummel, S.; Scarpa, F.; Di Maio, D.; Lira, C.; Ruzzene, M.; Remillat, C.D.L.; Lim, T.C.; Rajasekaran, R.; Patsias, S. Dynamic behavior of auxetic gradient composite hexagonal honeycombs. Compos. Struct. 2016, 149, 114-124. [CrossRef] 
62. Lim, T.C. Composite microstructures with Poisson's ratio sign switching upon stress reversal. Compos. Struct. 2019, 209, 34-44. [CrossRef]

63. Lim, T.C. 2D structures exhibiting negative area compressibility. Phys. Status Solidi B 2017, $254,1600682$. [CrossRef]

64. Lim, T.C. Metamaterials with Poisson's ratio sign toggling by means of microstructural duality. SN Appl. Sci. 2019, 1, 176.

(c)

(C) 2019 by the author. Licensee MDPI, Basel, Switzerland. This article is an open access article distributed under the terms and conditions of the Creative Commons Attribution (CC BY) license (http://creativecommons.org/licenses/by/4.0/). 